\title{
Exercise training with negative pressure ventilation improves exercise capacity in patients with severe restrictive lung disease: a prospective controlled study
}

\author{
Shu-Chuan Ho ${ }^{1,3}$, Horng-Chyuan Lin ${ }^{1}$, Han-Pin Kuo ${ }^{1,2}$, Li-Fei Chen'1, Te-Fang Sheng ${ }^{1}$, Wen-Ching Jao', \\ Chun-Hua Wang ${ }^{1}$ and Kang-Yun Lee ${ }^{1,2^{*}}$
}

\begin{abstract}
Background: Exercise training is of benefit for patients with restrictive lung disease. However, it tends to be intolerable for those with severe disease. We examined whether providing ventilatory assistance by using negative pressure ventilators (NPV) during exercise training is feasible for such patients and the effects of training.

Methods: 36 patients with restrictive lung disease were prospectively enrolled for a 12-week multidisciplinary rehabilitation program. During this program, half of them ( $n: 18 ; 60.3 \pm 11.6$ years; 6 men; FVC: $32.5 \pm 11.7 \%$ predicted ) received regular sessions of exercise training under NPV, whilst the 18 others ( $59.6 \pm 12.3$ years; 8 men; FVC: $37.7 \pm 10.2 \%$ predicted) did not. Exercise capacity, pulmonary function, dyspnea and quality of life were measured. The primary endpoint was the between-group difference in change of 6 minute-walk distance (6MWD) after 12 weeks of rehabilitation.

Results: All patients in the NPV-exercise group were able to tolerate and completed the program. The betweengroup differences were significantly better in the NPV-exercise group in changes of 6MWD $(34.1 \pm 12.7 \mathrm{~m}$ vs. -32.5 $\pm 17.5 \mathrm{~m} ; P=0.011)$ and St George Score $(-14.5 \pm 3.6$ vs. $11.8 \pm 6.0 ; P<0.01)$. There was an improvement in dyspnea sensation (Borg's scale, from $1.4 \pm 1.5$ point to $0.8 \pm 1.3$ point, $P=0.049$ ) and a small increase in FVC (from $0.85 \pm$ $0.09 L$ to $0.91 \pm 0.08 L, P=0.029)$ in the NPV-exercise group compared to the control group.
\end{abstract}

Conclusion: Exercise training with NPV support is feasible for patients with severe restrictive lung diseases, and improves exercise capacity and health-related quality of life.

Keywords: Restrictive lung disease, Negative pressure ventilation, Exercise training, Exercise capacity, Health-related quality of life

\section{Background}

Patients with restrictive lung diseases (RLD) often suffer from dyspnea, fatigue and impairments in muscle force, exercise tolerance, and activity of daily life (ADL), leading to a decrease in health-related quality of life (QoL) [1-3]. This is due to a complicated combination of impairments in ventilation and gas exchange and a number of

\footnotetext{
* Correspondence: lee4949@ms41.hinet.net

'Department of Thoracic Medicine, Chang Gung Memorial Hospital, Chang Gung University College of Medicine, 199 Tun-Hwa North Road, Taipei, Taiwan ${ }^{2}$ Chang Gung University, Department of Medicine, College of Medicine, Taoyuan, Taiwan

Full list of author information is available at the end of the article
}

secondary changes such as peripheral muscle, cardiac, nutritional, and psychological impairments [4]. Following the consensus of pulmonary rehabilitation (PR) in chronic obstructive pulmonary disease (COPD) [5,6], evidence is growing that patients with RLD, which share many manifestations and physiological impairments with COPD, may also benefit from PR. Early randomized control studies have reported an improvement in exercise capacity and QoL after $8-10$ weeks of exercise training $[7,8]$. The benefits disappeared after 6 months, however this could be overcome by longer programs extending to 24 weeks which showed even better results [9]. Although the latter

\section{Biomed Central}


studies were weakened by the non-randomized and noncontrolled design, the message is important. As many of those likely to be enrolled tend to have early and profound exercise-induced oxygen desaturation, dyspnea and peripheral muscle weakness, an extended program may offset the low initial training load [4]. Alternatively, exercise training with some assistance, and in particular ventilatory support, may be useful, although this has not yet been extensively tested.

Non-invasive mechanical ventilatory techniques include the use of negative and positive pressure ventilators. Using non-invasive positive pressure ventilators (NPPV) as an aid during exercise training has been reported to enable a higher intensity of training for patients with severe COPD, leading to larger improvements in exercise performance $[10,11]$. In patients with severe RLD, NPPV during exercise has been shown to improve oxygenation and exercise tolerance [12], whilst the effect on exercise training has not been studied. Nevertheless, some practical drawbacks such as discomfort from the mouthpiece or mask [10] can result in a substantial number of patients dropping out [13]. Alternatively, negative pressure ventilators (NPV) (iron lungs) have been shown to be as effective as NPPV in certain conditions such as acute exacerbation of COPD, and to play a role in those who cannot tolerate a facial mask [14]. Short-term intermittent NPV has been demonstrated to improve ventilation and increase $\mathrm{PaO}_{2}$ in patients with severe hypercapnic COPD [15].

We hypothesized that an exercise training PR program with NPV support in patients with severe RLD would increase exercise capacity, decrease dyspnea sensation, and improve the QoL. We tested this hypothesis by conducting a prospective controlled study with exercise capacity as the primary endpoint.

\section{Materials and methods}

\section{Subjects}

This prospective, non-randomized, controlled study was carried out from 30 November 2008 to 30 May 2010 at Chang Gung Memorial Hospital, a university hospital in Linko, Taiwan. All patients with severe RLD referred by the chest physicians from the outpatient department for pulmonary rehabilitation were eligible for inclusion if they were clinically stable and presented with forced vital capacity $(\mathrm{FVC}) \leq 50 \%$ predicted. Patients were excluded if they had a coexisting airway obstruction (forced expiratory volume in one second $\left.\left(\mathrm{FEV}_{1}\right) / \mathrm{FVC} \leq 70 \%\right)$, other respiratory diseases such as asthma, tuberculosis, COPD, bronchiectasis, cancer, and acute infection in the last 3 months. The decision to receive NPV-supported exercise training was made by the chest physician after discussing the program with the patients and their family. The protocol was approved by the institutional review board (CGMH 971032B). Each patient gave informed consent to participate.

\section{Study design}

All patients attended a 12-week, twice-a-week, outpatient, multidiscipline PR program, consisting of breathing retraining, limb exercise training and an education program (lectures and discussions on RLD, medication use and nutrition, relaxation techniques, and home exercise). The patients in the NPV-exercise group also received endurance exercise training consisting of 20 minutes of submaximal cycle ergometry, combined strength/resistance training of the upper limbs through a series of 10 repetitions against progressive resistance, and specific training of respiratory muscles and breathing technique exercises of the thoracic and abdominal muscles, guided by Borg's scale (score between 4 to 6 for dyspnea and fatigue), with the support of $\mathrm{NPV}$ (control + sign model delivered by $-20 \mathrm{cmH}_{2} \mathrm{O}$ delivery pressure and $+3 \mathrm{cmH}_{2} \mathrm{O}$ base pressure, 12 cycles per minute, inspiratory time to expiratory time (I/E) ratio 2.5 ). To determine the exercise capacity, a symptom-limited bicycle ergometry test as previous reported [16] was performed using a ramp 10, 15, or 20 protocol, depending on the patient's fitness. The load was increased every minute by 10,15 , or 20 Watts, respectively, in such a way that patients could reach their maximal workload within 10 minutes. The test was terminated on the basis of the patient's symptoms or at the physician's discretion. Maximal workload in Watts at maximal performance was taken for analysis. $40-60 \%$ of the maximal workload was used as the intensity of training. All patients were established on an unsupervised home endurance exercise program of 20-30 minutes walk, continuously or intermittently (in sessions lasting 10 or more minutes) per day, guided by $40-60 \%$ of target heart rate or 4-6 on the modified Borg scale, with the aim of achieving 3 to 5 exercise sessions per week. Oxygen was provided by a nasal cannula to maintain $\mathrm{SatO}_{2} \geq 90 \%$ during the whole PR course for all patients.

\section{Clinical assessments}

$\mathrm{FEV}_{1}, \mathrm{FVC}$ and $\mathrm{FEV}_{1} / \mathrm{FVC}$ were recorded using a spirometer (ST-250, Fukuda Sangyo Co. Ltd.) and 6-minute walk test (6MWT) was performed with a pulse oximeter by a finger transducer (Criticare Systems Inc.) according to the ATS guidelines $[17,18]$. The dyspnea score was rated by patients according to a modified Borg's scale [19], in which words describing increasing degrees of dyspnea were assigned to numbers between 0 (no dyspnea) and 10 ( maximal dyspnea).

Health-related quality of life (HRQoL) was assessed using St. George's Respiratory Questionnaire (SGRQ), a self-administered questionnaire measuring impaired health and perceived HRQoL for airways disease. It consists of 76 items including symptoms, activity, impact and total scores. The scores range from 0 (no impairment) to 100 (the worst impairment), in which higher scores connoted greater distress and worse HRQoL [20]. 
Maximal voluntary isometric muscle force of the right and left extremity of the following muscle groups was measured: extension of the knees and flexion of the elbows, using a handheld dynamometer (Hoggan Health Industry, West Jordon, Utah USA). The test was repeated three times, and the best result of either side was used in the analyses.

\section{Statistic analysis}

Descriptive statistics were expressed as mean \pm SD. Between group changes in pulmonary functions, 6MWD, Borg score and SGRQ scores were analyzed using the Mann-Whitney U test. 6MWD, FVC, FEV 1 and SGRQ at enrollment, and after 4 weeks, 12 weeks and 52 weeks were compared using the Friedman test with Dunn's multiple comparison post-test for the NPV-exercise group. SGRQ before and after the 12-week PR program was compared by the Wilcoxon signed rank test. Data were presented as mean $\pm \mathrm{SD}$. A $p$ value less than 0.05 was considered significant. Data analyses were performed using the GraphPad Prism 5.01 software package (GraphPad Software, San Diego, CA).

\section{Results}

\section{Study population}

Eighteen patients (6 males and 12 females, mean age $60.3 \pm 11.6$ years; FVC: $32.5 \pm 11.7 \%$ predicted) in the NPV-exercise group, and 18 patients (8 males and 10 females, mean age $59.6 \pm 12.3$ years; FVC: $37.7 \pm 10.2 \%$ predicted) in the control group were enrolled. Before entry into the program, most of the patients could not tolerate exercise training without NPV support. All of the eighteen patients in the NPV-exercise group completed the 12-week NPV-exercise program.

The baseline characteristics of both groups are shown in Table 1. There were no significant differences in age,

Table 1 Characteristics of patients with restrictive lung disease in both groups

\begin{tabular}{lcc}
\hline Characteristics & $\begin{array}{c}\text { Non-NPV } \\
\text { exercise group }\end{array}$ & $\begin{array}{c}\text { NPV-exercise } \\
\text { group }\end{array}$ \\
\hline Number of patients & 18 & 18 \\
Age, years & $59.6 \pm 12.3$ & $60.3 \pm 11.6$ \\
Gender, M/F & $8 / 10$ & $6 / 12$ \\
BMI, kg/m ${ }^{2}$ & $19.7 \pm 5.0$ & $21.5 \pm 4.6$ \\
FVC, L & $1.05 \pm 0.34$ & $0.85 \pm 0.37$ \\
FVC, \% predicted & $37.7 \pm 10.2$ & $32.5 \pm 11.7$ \\
FEV 1, L & $0.88 \pm 0.26$ & $0.72 \pm 0.32$ \\
FEV $_{1}, \%$ predicted & $42.2 \pm 2.4$ & $36.9 \pm 13.6$ \\
FEV $_{1} /$ FVC, \% & $84.2 \pm 8.3$ & $83.1 \pm 13.6$ \\
$6 M W D$, m & $362.8 \pm 99.4$ & $371.3 \pm 77.9$ \\
Borg score, median(range) & $0.5(0-4)$ & $1.25(0-4)$ \\
\hline
\end{tabular}

BMI, Body mass index; 6MWD, 6-min walk distance. gender, BMI, FVC, $\mathrm{FEV}_{1}, \mathrm{FEV}_{1} / \mathrm{FVC}, 6 \mathrm{MWD}$ and Borg scales between the two groups. Eight patients had chest wall deformities and 10 patients had interstitial lung diseases in the NPV-exercise group, while 6 patients had chest wall deformities and 12 patients had interstitial lung disease in the control group. Patients in both groups had low BMI $\left(19.7 \pm 5.0 \mathrm{~kg} / \mathrm{m}^{2}\right.$ vs. $\left.21.5 \pm 4.6 \mathrm{~kg} / \mathrm{m}^{2}\right)$, poor SGRQ scores (42.6 \pm 4.6 vs. $44.6 \pm 4.8)$ and poor exercise tolerance (6MWD, $362.8 \pm 99.4 \mathrm{~m}$ vs. $371.3 \pm 77.9 \mathrm{~m}$ ) with equal severity. After the end of the 12-week study, observational data were collected for those who regularly came back to our OPD until 52 weeks. These patients $(n=14)$ were all in the NPV-exercise. The ratio between IPF and CWD was almost unchanged at each time of evaluation, being $10 / 8,8 / 5,10 / 8$ and $7 / 7$ at week $0,4,12$ and 52 . As most of the patients in the control group were lost to follow-up by 52 weeks, their clinical data were not available for analysis.

\section{Changes in 6MWD and dyspnea sensation}

Table 2 shows the effect of the PR program on 6MWT, pulmonary function and quality of life. At the end of 12 weeks, patients in the NPV-exercise group had an increase in 6MWD by $34.1 \pm 12.7 \mathrm{~m}$ (Table 2 and Figure 1A, $371.3 \pm 77.9 \mathrm{~m}$ vs. $405.4 \pm 78.1 \mathrm{~m} ; P=0.016)$. In contrast, patients in the control group had a trend of a decrease by $32.5 \pm 17.5 \mathrm{~m}(362.8 \pm 99.4 \mathrm{~m}$ vs. $330.3 \pm 94.4 \mathrm{~m} ; P=$ $0.080)$. The between group difference was significant (Figure $1 \mathrm{~B}, P=0.011)$. The increase in $6 \mathrm{MWD}$ in the NPV-exercise group started at 4 weeks, reached statistical significance at 12 weeks, and disappeared at 52 weeks (Figure 1C).

The improvement in 6MWD in the NPV-exercise group was accompanied by an improvement in resting dyspnea sensation as determined by the modified Borg scale (Table $1,1.4 \pm 1.5$ points vs. $0.8 \pm 1.3$ points, $P=$ 0.049). In contrast, there was no change in Borg scale $(1.3 \pm 0.4$ points vs. $1.6 \pm 0.4$ points, $P=0.573)$ in the control group. Both groups of patients suffered from $\mathrm{O}_{2}$ desaturation during 6MWT, which was not improved in either group at 12 weeks.

\section{Changes in pulmonary function}

Pulmonary function was improved in the NPV-exercise group after 12 weeks of training (Table 2, Figures 2A and $3 \mathrm{~A})$; FVC improved by $53.3 \pm 26.8 \mathrm{ml}(0.85 \pm 0.09 \mathrm{~L}$ vs. $0.91 \pm 0.08 \mathrm{~L}, P=0.029)$, and $\mathrm{FEV}_{1}$ improved by 50.0 $\pm 21.0 \mathrm{ml}(0.72 \pm 0.08 \mathrm{~L}$ vs. $0.77 \pm 0.08 \mathrm{~L}, P=0.029)$, being equivalent to increases of $2.5 \pm 1.0 \%$ predicted and $3.4 \pm 1.2 \%$ predicted, respectively. In contrast, pulmonary function did not change in the control group (Table 2 and Figures 2A and 3A). However, the between group differences in either $\triangle \mathrm{FVC}$ or $\triangle \mathrm{FEV}_{1}$ did not reach statistical significance (Figures $2 \mathrm{~B}$ and $3 \mathrm{~B}$ ). Both pulmonary 
Table 2 Changes in pulmonary function, 6-minute walk test, and health-related quality of life before and after 12 weeks of pulmonary rehabilitation

\begin{tabular}{|c|c|c|c|c|}
\hline & \multicolumn{2}{|c|}{ Non-NPV-exercise group } & \multicolumn{2}{|c|}{ NPV-exercise group } \\
\hline & $\begin{array}{c}\text { Baseline } \\
(n=18)\end{array}$ & $\begin{array}{c}12 \text { weeks } \\
(n=18)\end{array}$ & $\begin{array}{c}\text { Baseline } \\
(n=18)\end{array}$ & $\begin{array}{c}12 \text { weeks } \\
(n=18)\end{array}$ \\
\hline FVC, \% predicted & $37.7 \pm 2.4$ & $37.9 \pm 3.2$ & $32.6 \pm 2.8$ & $35.1 \pm 2.7^{a}$ \\
\hline $\mathrm{FEV}_{1}, \%$ predicted & $42.2 \pm 2.9$ & $43.9 \pm 4.3$ & $36.9 \pm 3.2$ & $40.3 \pm 3.3^{a}$ \\
\hline $\mathrm{FEV}_{1} / \mathrm{FVC}, \%$ & $84.1 \pm 8.6$ & $83.6 \pm 7.8$ & $82.9 \pm 9.4$ & $83.5 \pm 10.8$ \\
\hline $6 \mathrm{MWD}, \mathrm{m}$ & $362.8 \pm 99.4$ & $330.3 \pm 94.4$ & $371.3 \pm 77.9$ & $405.4 \pm 78.1^{a}$ \\
\hline $\mathrm{SaO} 2, \%$ pre/post $6 \mathrm{MWT}$ & $94.0 / 81.4$ & $93.2 / 76.8$ & $93.9 / 77.0$ & $94.6 / 79.1$ \\
\hline HR, pre/ post 6MWT & $98.2 / 125.8$ & $101.4 / 127.7$ & $103.3 / 126.7$ & $92.0 / 123.4$ \\
\hline Borg, pre/ post 6MWT & $0.5 / 5.0$ & $1.5 / 7.0$ & $1.25 / 5.0$ & $0 / 4.5^{\mathrm{a}}$ \\
\hline (range) & $(0-4) /(3-10)$ & $(0-4) /(2-9)$ & $(0-4) /(4-8)$ & $(0-4) /(1-8)$ \\
\hline \multicolumn{5}{|l|}{ Limb muscle power } \\
\hline R-upper limb, Ib & $32.9 \pm 1.8^{b}$ & $32.3 \pm 1.6^{b}$ & $31.0 \pm 2.1^{c}$ & $33.5 \pm 2.2^{a_{1} c}$ \\
\hline L-upper limb, Ib & $30.2 \pm 3.5^{b}$ & $33.0 \pm 4.7^{b}$ & $29.6 \pm 1.6^{c}$ & $30.3 \pm 1.6^{c}$ \\
\hline R-low limb, Ib & $44.3 \pm 3.9^{b}$ & $46.2 \pm 4.9^{b}$ & $38.5 \pm 3.0^{c}$ & $41.4 \pm 2.3^{c}$ \\
\hline L-low limb. Ib & $41.2 \pm 3.4^{b}$ & $41.3 \pm 4.6^{b}$ & $38.2 \pm 2.7^{c}$ & $40.7 \pm 2.2^{c}$ \\
\hline \multicolumn{5}{|l|}{ SGRQ } \\
\hline Symptom score & $48.2 \pm 6.0^{e}$ & $46.5 \pm 6.1^{e}$ & $54.6 \pm 5.0$ & $24.5 \pm 4.0^{\mathrm{a}}$ \\
\hline Active score & $61.6 \pm 6.0^{e}$ & $72.3 \pm 6.1^{e}$ & $53.7 \pm 5.8$ & $45.9 \pm 5.6^{a}$ \\
\hline Impacts score & $30.0 \pm 4.2^{\mathrm{e}}$ & $46.7 \pm 7.0^{\mathrm{a}, \mathrm{e}}$ & $36.2 \pm 5.7$ & $22.6 \pm 5.1^{\mathrm{a}}$ \\
\hline Total score & $42.6 \pm 4.6^{e}$ & $54.4 \pm 4.9^{e}$ & $44.6 \pm 4.8$ & $30.0 \pm 4.4^{\mathrm{a}}$ \\
\hline
\end{tabular}

Values are mean \pm SD.

${ }^{a} \mathrm{p}<0.05$, baseline vs. 12 weeks.

b only 6 patients in the non-NPV exercise group received limb muscle tests.

c 17 patients in the NPV exercise group received limb muscle tests.

e only 10 patients in the non-NPV exercise group completed the SGRQ at 12 weeks.

functions in the NPV-exercise group had a trend of increase at 4 weeks, which became significant at the end of 12-week training program (Figures $2 \mathrm{C}$ and $3 \mathrm{C}$ ). Whilst $\mathrm{FEV}_{1}$ declined to a level similar to that at baseline at 52 weeks (Figure 3C), the increase in FVC was sustained at this time point (Figure 2C). The ratio of $\mathrm{FEV}_{1} / \mathrm{FVC}$ did not change in either group at 12 weeks compared with that at baseline (Table 2).

\section{Changes in health-related quality of life}

All the 18 patients in the NPV-exercise group completed the SGRQ test, whereas only 10 out of the 18 patients in the control group did. The other 8 patients did not receive the test for personal reasons. The total SGRQ score at 12 weeks decreased by $14.5 \pm 3.6$ (Table 2 and Figure $4 \mathrm{~A}, \quad 44.6 \pm 20.3$ vs. $30.0 \pm 18.8, \quad P=0.009)$ compared with that at baseline in the NPV-exercise group. Improvements in SGRQ were consistently seen in the symptom score $(54.6 \pm 21.0$ vs. $24.5 \pm 16.8, P<$ $0.001)$, the activity score $(53.7 \pm 24.6$ vs. $45.9 \pm 23.7, P=$ $0.048)$, and the impact score ( $36.2 \pm 24.2$ vs. $22.6 \pm 21.6$, $P=0.077)$. Ten patients in the control group completed the SGRQ. An improvement was not seen in this group, and the impact score even deteriorated $(30.0 \pm 13.3$ vs. $46.7 \pm 22.2, P=0.04)$. The between group difference in $\triangle$ SGRQ was significant (Figure 4B, $P<0.01$ ).

Effects of NPV-exercise training vs. Control in patients with interstitial lung disease and patients with chest wall deformities

To see whether NPV-exercise training benefited distinct subgroups of patients, results were separately analyzed for patients with interstitial lung disease (ILD) and chest wall deformities (CWD) (Table 3). FVC and FEV increased by $4.2 \pm 4.1 \%$ predicted $(36.3 \pm 13.0 \%$ vs. 40.5 $\pm 11.6 \%, P<0.01)$ and $5.1 \pm 5.5 \%$ predicted $40.9 \pm 15.8 \%$ vs. $45.9 \pm 15.2 \%, P<0.05)$ in patients with ILD in the NPV-exercise group $(n=10)$. The between-group difference was significant in FVC $(P<0.01)$. These increases were not seen in CDW patients in the NPV-exercise group $(n=8)$. 6MWD increased by $45.8 \pm 87.5 \mathrm{~m}(352.3$ $\pm 52.8 \mathrm{~m}$ vs. $399.5 \pm 45.1 \mathrm{~m}, P<0.05)$ in ILD patients in the NPV-exercise group $(n=10)$. The between-group difference was significant $(P<0.05)$. A trend of increase was also seen in CDW patients $(n=8$, by $17.8 \pm 52.2 \mathrm{~m}$, $395.0 \pm 99.9 \mathrm{~m}$ vs. $412.8 \pm 109.8 \mathrm{~m})$. By contrast, both 

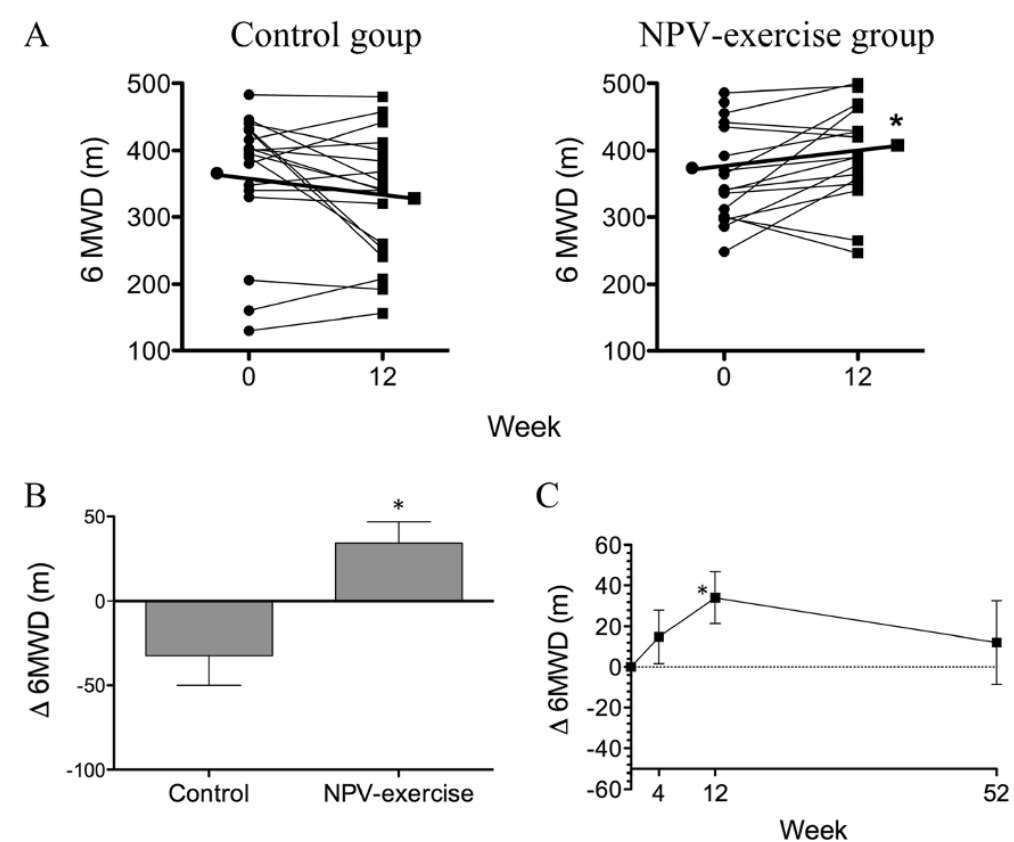

Figure 1 Effects of NPV-exercise training vs. control on 6-minute walk distance. A. Individual changes of 6MWD in both groups before and after the 12-week course (Control, $n=18$; NPV-exercise, $n=18$ ). B. Comparisons of delta-6MWD ( $\Delta 6 \mathrm{MWD}$; changes from the base line after 12 weeks; mean \pm SD) between both groups (Control, $n=18$; NPV-exercise, $n=18$ ). C. Time course of $6 \mathrm{MWD}$ in the NPV-exercise group $(n=14)$ during the 12 months.

subgroups of patients had a trend of disease in 6MWD by $29.7 \pm 74.3 \mathrm{~m}(n=12)$ and $47.2 \pm 54.2 \mathrm{~m}(n=6)$, respectively, in the control group. NPV-exercise training improved the total scores of SGRQ in patients with ILD $(n=10)$ and CWD $(n=8)$ by $17.5 \pm 18.5(54.5 \pm 21.3$ vs.
$37.0 \pm 21.1, P<0.05)$ and $10.9 \pm 10.2(32.2 \pm 10.0$ vs. 21.3 $\pm 11, P<0.05)$. This score had a trend of deterioration in both subgroups by $1.03 \pm 20.1 \quad(n=8)$ and $17.8 \pm 16.6$ $(n=2)$ in the control group. The between-group difference was significant for ILD $(P<0.01)$ and CWD $(P<0.05)$.
A

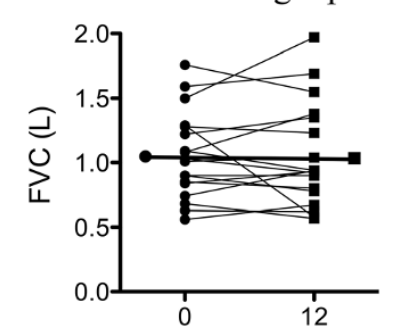

B

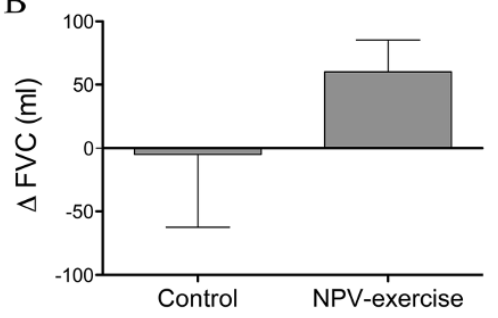

NPV-exercise group

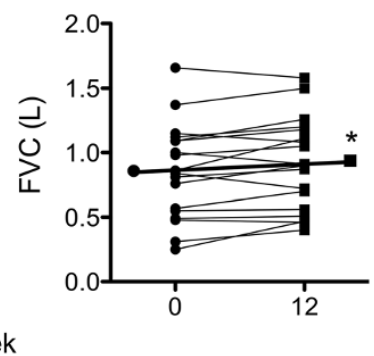

C

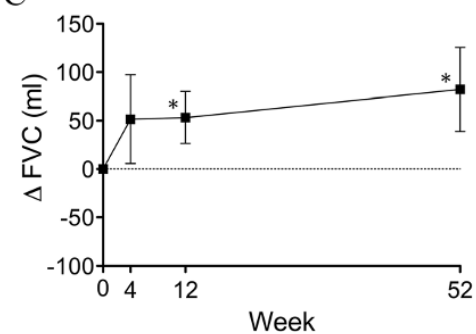

Figure 2 Effects of NPV-exercise training vs. control on FVC. A. Individual changes of FVC in both groups before and after the 12-week course (Control, $n=18$; NPV-exercise, $n=18)$. B. Comparisons of delta-FVC ( $\Delta$ FVC; changes from the base line after 12 weeks; mean \pm SD) between both groups (Control, $n=18$; NPV-exercise, $n=18$ ). C. Time course of FVC in the NPV-exercise group $(n=14)$ during the 12 months. 

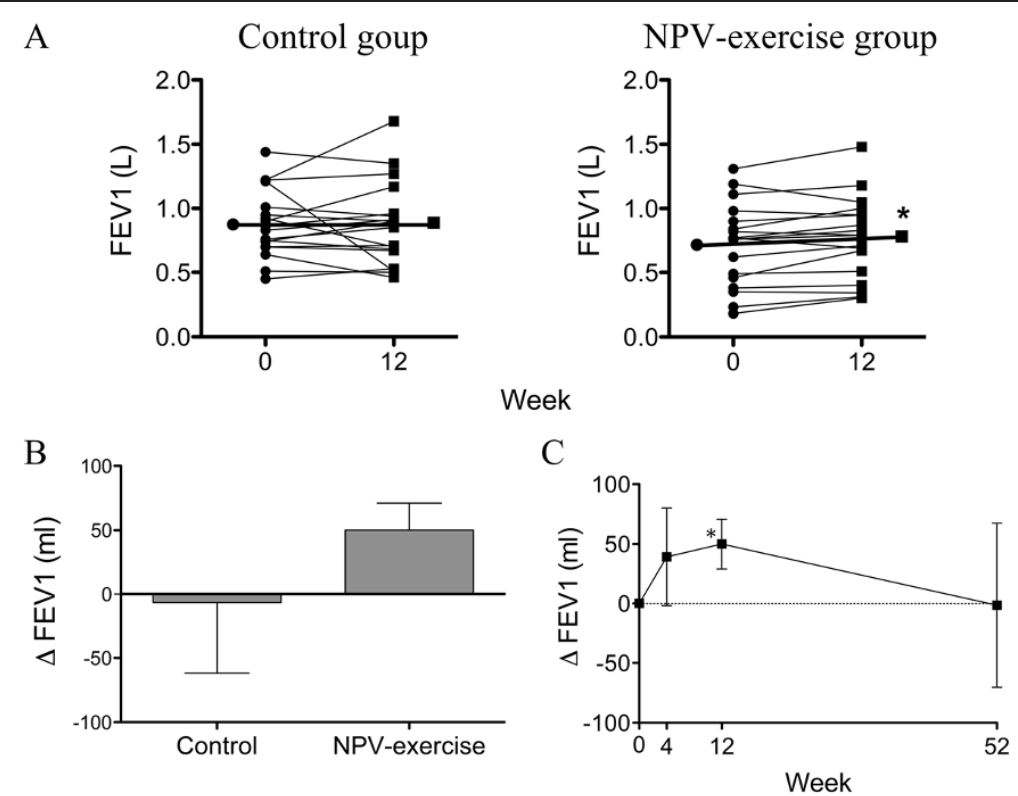

Figure 3 Effects of NPV-exercise training vs. control on $\mathrm{FEV}_{\mathbf{1}}$. A. Individual changes of $\mathrm{FEV}_{1}$ in both groups before and after the 12-week course (Control, $n=18$; NPV-exercise, $n=18)$. B. Comparisons of delta-FEV $\left(\Delta \mathrm{FEV}_{1}\right.$; changes from the base line after 12 weeks; mean $\left.\pm \mathrm{SD}\right)$ between both groups (Control, $n=18$; NPV-exercise, $n=18$ ). C. Time course of $\Delta \mathrm{FEV}_{1}$ in the NPV-exercise group $(n=14)$ during the 12 months.
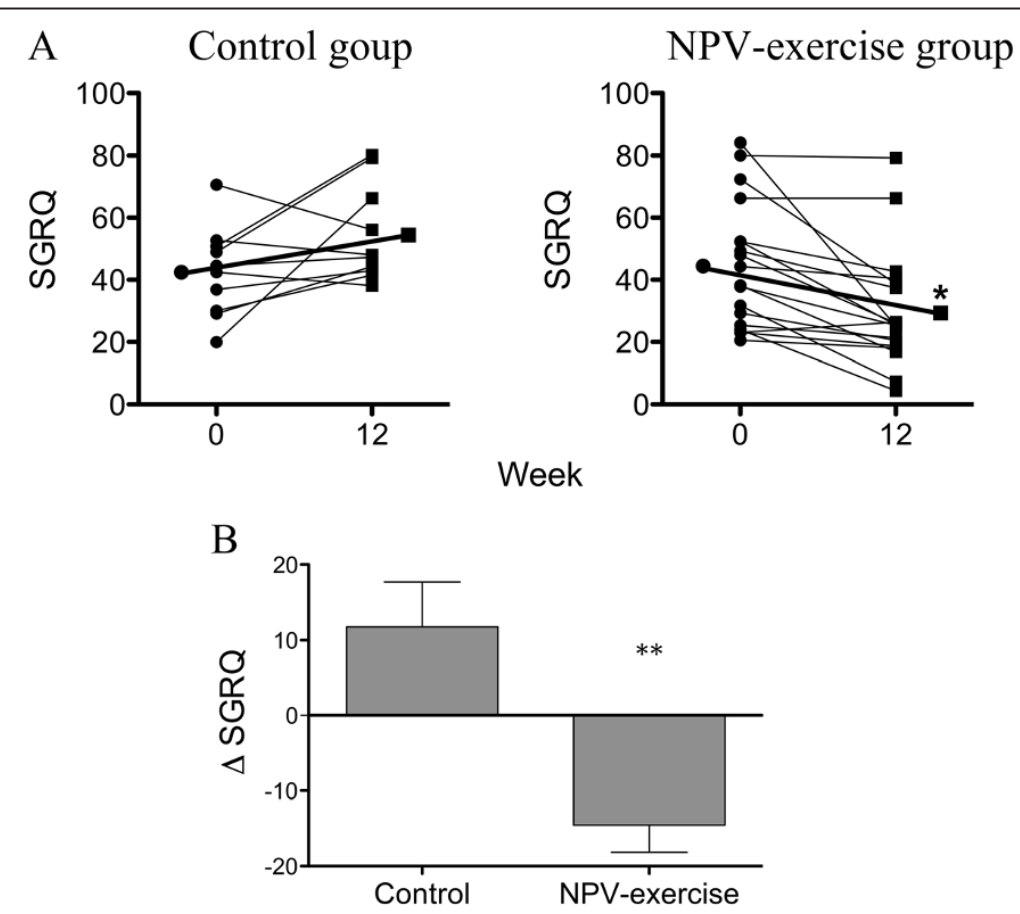

Figure 4 Effects of NPV-exercise training vs. control on health-related quality of life. A. Individual changes of SGRQ total scores in both groups before and after the 12-week course (Control, $n=10$; NPV-exercise, $n=18$ ). B. Comparisons of St. George's Respiratory Questionnaire (SGRQ) total score ( $\triangle \mathrm{SGRQ}$; changes from the base line after 12 weeks mean $\pm \mathrm{SD}$ ) between both groups (Control, $n=10$; NPV-exercise, $n=18$ ). 
Table 3 Changes in pulmonary function, 6-minute walk test, and health-related quality of life before and after 12 weeks of pulmonary rehabilitation in patients with interstitial lung disease vs. chest Wall disease

\begin{tabular}{|c|c|c|c|c|}
\hline & \multicolumn{2}{|c|}{ Non-NPV-exercise group } & \multicolumn{2}{|c|}{ NPV-exercise group } \\
\hline & Baseline & 12 weeks & Baseline & 12 weeks \\
\hline \multicolumn{5}{|l|}{ FVC, \% predicted } \\
\hline ILD & $40.3 \pm 10.3$ & $38.4 \pm 13.5$ & $36.3 \pm 13.0$ & $40.5 \pm 11.6^{b, c}$ \\
\hline Chest wall & $32.7 \pm 8.6$ & $37.0 \pm 14.5$ & $28.0 \pm 8.5$ & $28.3 \pm 7.4$ \\
\hline \multicolumn{5}{|c|}{$\mathrm{FEV}_{1}, \%$ predicted } \\
\hline ILD & $45.6 \pm 11.8$ & $43.8 \pm 18.2$ & $40.9 \pm 15.8$ & $45.9 \pm 15.2^{\mathrm{a}}$ \\
\hline Chest wall & $35.3 \pm 11.3$ & $44.2 \pm 20.2$ & $31.9 \pm 8.6$ & $33.3 \pm 8.0$ \\
\hline \multicolumn{5}{|l|}{$\mathrm{FEV}_{1} / \mathrm{FVC}, \%$} \\
\hline ILD & $81.8 \pm 6.8$ & $84.4 \pm 7.9$ & $82.3 \pm 9.7$ & $81.0 \pm 11.8$ \\
\hline Chest wall & $88.8 \pm 10.6$ & $82.2 \pm 8.1$ & $83.8 \pm 9.7$ & $86.6 \pm 9.1$ \\
\hline \multicolumn{5}{|l|}{ 6MWD, m } \\
\hline ILD & $385.2 \pm 82.6$ & $355.3 \pm 85.0$ & $352.3 \pm 52.8$ & $399.5 \pm 45.1^{a}$ \\
\hline Chest wall & $318.2 \pm 122.4$ & $288.0 \pm 99.3$ & $395.0 \pm 99.9$ & $412.8 \pm 109.8$ \\
\hline \multicolumn{5}{|c|}{$\mathrm{SaO} 2, \%$ pre/post $6 \mathrm{MWT}$} \\
\hline ILD & $94.3 / 78.7$ & $93.1 / 78.6$ & $96.0 / 80.5$ & $96.3 / 83.1$ \\
\hline Chest wall & $94.8 / 77.3$ & $93.3 / 73.3$ & $91.3 / 72.6$ & $92.4 / 74.1$ \\
\hline \multicolumn{5}{|c|}{ Borg, pre/ post 6MWT } \\
\hline ILD & $0.9 / 5.1$ & $1.5 / 5.8$ & $1.7 / 5.5$ & $0.8 / 4.8$ \\
\hline Chest wall & $2.0 / 5.8$ & $1.7 / 5.8$ & $1.1 / 5.3$ & $0.8 / 5.0$ \\
\hline \multicolumn{5}{|l|}{ SGRQ } \\
\hline \multicolumn{5}{|c|}{ Symptom score } \\
\hline ILD & $47.6 \pm 21.5^{c}$ & $42.1 \pm 19.3^{c}$ & $61.7 \pm 16.6^{\mathrm{e}}$ & $29.5 \pm 19^{\mathrm{b}, \mathrm{e}}$ \\
\hline Chest wall & $50.3 \pm 5.8^{d}$ & $64.1 \pm 0.2^{d}$ & $53.7 \pm 5.8^{f}$ & $45.9 \pm 5.6^{\mathrm{a}, \mathrm{f}}$ \\
\hline \multicolumn{5}{|l|}{ Active score } \\
\hline ILD & $62.2 \pm 21.5$ & $73.7 \pm 12.8$ & $61.4 \pm 27.4$ & $53.5 \pm 23.2$ \\
\hline Chest wall & $59.5 \pm 0.0$ & $66.4 \pm 18.8$ & $43.9 \pm 17.6$ & $36.5 \pm 22.0$ \\
\hline \multicolumn{5}{|l|}{ Impacts score } \\
\hline ILD & $29.3 \pm 13.6$ & $43.9 \pm 19.2$ & $48.3 \pm 25.3$ & $30.0 \pm 25.3^{\mathrm{a}}$ \\
\hline Chest wall & $32.9 \pm 16.7$ & $58.0 \pm 38.9$ & $21.2 \pm 11.7$ & $13.5 \pm 12.2$ \\
\hline \multicolumn{5}{|l|}{ Total score } \\
\hline ILD & $42.3 \pm 16.0$ & $52.6 \pm 14.0$ & $54.5 \pm 21.3$ & $37.0 \pm 21.1^{\mathrm{a}}$ \\
\hline Chest wall & $43.8 \pm 9.8$ & $61.6 \pm 26.4$ & $32.2 \pm 10.0$ & $21.3 \pm 11.5^{a}$ \\
\hline
\end{tabular}

Values are mean \pm SD.

${ }^{\mathrm{a}} \mathrm{p}<0.05$, baseline vs. 12 weeks; $^{\mathrm{b}} \mathrm{p}<0.01$, baseline vs. 12 weeks; ${ }^{\mathrm{c}} n=8 ;{ }^{\mathrm{d}} n=2 ;{ }^{\mathrm{e}} n=10 ;{ }^{\mathrm{f}} n=8$.

\section{Discussion}

The present study investigated the effect of exercise training under the support of NPV for patients with severe RLD. This study was designed in a prospective controlled setting. The between group difference in $\triangle 6 \mathrm{MWD}$, the primary end point, reached statistical difference in favor of the NPV-exercise group. An improvement in SGRQ was also seen in the NPV-exercise group compared with the control group.

Although exercise training PR programs can improve exercise capacity and HRQoL in patients with RLD for those with severe disease [8], it tends to be intolerable. The patients enrolled for PR training in the present study (FVC $32.5 \pm 11.7 \%$ predicted) appeared to be more severe than those in previous reports (FVC 48-68\% predicted) [7-9]. Almost none of the patients were able to perform functional exercise tasks because of severe ventilation impairment accompanied with muscle weakness and deconditioning. Muscle weakness can be overcome by ventilation support as demonstrated by Borel et al [12]. With the assistance of NPV, all patients in the study group well tolerated the exercise PR program, and 
they also achieved even better results (difference in 6MWT between groups $66.6 \mathrm{~m}$ ) than those demonstrated in earlier reports $(35.0-46.3 \mathrm{~m})[7,8]$. This difference is greater than the minimal clinical important difference (MCID) for COPD (54 m) [21] and that for idiopathic pulmonary fibrosis $(24-45 \mathrm{~m})$ [22]. Nevertheless, our patients comprised a heterogeneous group of patients with different diseases, for most of which the MCID has not been defined. Whether the improvement in exercise capacity reaches clinical significance needs further study to confirm.

Ventilation support by using NPPV can unload ventilator muscles, leading to a reduction in breathing work and dyspnea sensation [23]. This unloading has also been demonstrated to improve peripheral muscle oxygenation in the absence of changes in systemic oxygen delivery in patients with advanced COPD during highintensity exercise, probably due to redistribution of cardiac output to appendicular muscles [24]. This will not only allow a greater intensity of exercise but also allow it to be sustained for longer periods to achieve a training effect [11]. Although not proven directly, NPV may also benefit patients with severe RLD through similar mechanisms such that patients may be able to tolerate exercise training to an extent of adequate intensity. Increased peripheral muscle oxygenation may also contribute to a better training efficacy. Although more data is necessary to support this theory, this concept may be a rationale to introduce NPV during exercise training for patients with RLD with less severity, or even other respiratory diseases such as COPD.

The present study showed that an NPV-assisted exercise program remarkably improved health-related quality of life (HRQoL), as demonstrated by the SGRQ scores. Patients in the NPV-exercise group had clinically significant decreases in total and almost all components of the scores, e.g. symptoms, activity and impact. This is consistent with most previous reports observing the effects of exercise training on HRQoL in a range of RLD using the Chronic Respiratory Disease Questionnaire [8,9] or the SGRQ [7]. Both resting and post-exercise dyspnea sensation, determined by the Borg score, also improved. This improvement was not associated with changes of muscle power or $\mathrm{O}_{2}$ saturation. Interestingly, we observed a significant increase in pulmonary function, including $\mathrm{FEV}_{1}$ and $\mathrm{FVC}$, after 12 weeks of training. Importantly, the increase in FVC (2.5\% predicted) reached the recently defined minimal clinical important difference for IPF [25], in which the small changes of $2-6 \%$ were thought to be clinically important. This was not seen in previous reports on exercise training for RLD patients $[8,9]$. Further study is needed to see whether this improvement in pulmonary function has clinical significance. Of note, Smith et al. reported their experience of treating kyphotic patients with nocturnal non-invasive ventilation, either with an individually constructed cuirass shell and a negative pressure pump or nasal intermittent positive pressure ventilation, long-term use of which resulted in a significant increase in $\mathrm{FEV}_{1}$ and $\mathrm{FVC}$ [26]. As the between group difference in FVC in the present study, albeit with a trend, was not statistically significant, further studies enrolling more patients is necessary to confirm our observations.

The present study did not include a group of NPV without endurance training. It is therefore not conclusive whether the study group got benefits from NPV and/or exercise training. Guzun et al. recently reported that physical training at mild intensity, even below the level expected for a physiological training effect, can induce comparable changes in skeletal muscles oxidative energy metabolism in patients with COPD and sedentary healthy subjects [27]. Thus it is interesting to conduct a study to explore the pure effect of NPV or NPV with physical activity of mild intensity.

A limitation of the study is the non-randomized design. This is dictated by the fact that few patients were willing to be randomized in such kind of intervention. Nevertheless, the baseline characteristics were similar between the two groups such that a skewed population in each group, although cannot be completely excluded, became less likely. In addition, there is heterogeneity of patients. Subgroup analysis revealed that NPV-exercise training benefited both ILD and CWD patients in HRQoL. Whereas this training improved exercise capacity and pulmonary functions in ILD patients, it only had a trend of improvement (exercise capacity) or no effects (pulmonary functions) in CWD patients. Whether this training has clinically relevant effects on exercise capacity in these patients needs to be confirmed in a larger scale of study.

\section{Conclusions}

Ventilation support with NPV during exercise training is feasible for patients with severe RLD who are profoundly intolerant to exercise. In such patients, exercise training with NPV support increases exercise capacity and HRQoL to a level of clinical importance, at least in patients with ILD. Thus, NPV should be considered for patients with severe RLD who are not able to tolerate exercise training with adequate intensity. Our study also raises the possibility that NPV enhances the training effect of exercise through redistribution of cardiac output to the limb muscles, and that NPV increases pulmonary functions. Further studies to confirm these findings are warranted and may potentially extend the use of NPV in pulmonary rehabilitation for patients with RLD, and potentially for other chronic conditions with impairment in exercise tolerance. 


\section{Competing interests}

The authors have no conflicts of interest to disclose.

\section{Authors' contribution}

SCH conceived the idea, designed, carried out the study, performed the statistical analysis and were the main writers of the manuscript. HCL and HPK directed and supervised the study. LFC, TFS, WCJ and CHW assisted in subjects recruiting and helped to carry out the study. KYL directed the statistical analysis, data interpretation and manuscript preparation and writing. All authors read and approved the final manuscript.

\section{Acknowledgments}

The authors wish to thank the patients and personnel of the hospital unit for their cooperation during the course of this study.

\section{Funding}

This work was supported by grants to S.-C. Ho. from Chang Gung Memorial Hospital (CMRPG371891)

\section{Author details}

'Department of Thoracic Medicine, Chang Gung Memorial Hospital, Chang Gung University College of Medicine, 199 Tun-Hwa North Road, Taipei, Taiwan. ${ }^{2}$ Chang Gung University, Department of Medicine, College of Medicine, Taoyuan, Taiwan. ${ }^{3}$ School of Respiratory Therapy, College of Medicine, Taipei Medical University, Taipei, Taiwan.

Received: 29 November 2012 Accepted: 18 February 2013 Published: 19 February 2013

\section{References}

1. Hsia CC: Cardiopulmonary limitations to exercise in restrictive lung disease. Med Sci Sports Exerc 1999, 31:S28-S32.

2. Naji NA, Connor MC, Donnelly SC, McDonnell TJ: Effectiveness of pulmonary rehabilitation in restrictive lung disease. J Cardiopulm Rehabil 2006, 26:237-243.

3. Herridge MS, Cheung AM, Tansey CM, Matte-Martyn A, Diaz-Granados N, Al-Saidi F, Cooper AB, Guest CB, Mazer CD, Mehta S, et al: One-year outcomes in survivors of the acute respiratory distress syndrome. $N$ Engl $J$ Med 2003, 348:683-693.

4. Varadi RG, Goldstein RS: Pulmonary rehabilitation for restrictive lung diseases. Chest 2010, 137:247-248.

5. Casaburi R, ZuWallack R: Pulmonary rehabilitation for management of chronic obstructive pulmonary disease. N Engl J Med 2009, 360:13291335.

6. Ries AL, Bauldoff GS, Carlin BW, Casaburi R, Emery CF, Mahler DA, Make B, Rochester CL, Zuwallack R, Herrerias C: Pulmonary Rehabilitation: Joint ACCP/AACVPR Evidence-Based Clinical Practice Guidelines. Chest 2007, 131:4S-42S.

7. Nishiyama O, Kondoh Y, Kimura T, Kato K, Kataoka K, Ogawa T, Watanabe F, Arizono S, Nishimura K, Taniguchi H: Effects of pulmonary rehabilitation in patients with idiopathic pulmonary fibrosis. Respirology 2008, 13:394-399.

8. Holland AE, Hill CJ, Conron M, Munro P, McDonald CF: Short term improvement in exercise capacity and symptoms following exercise training in interstitial lung disease. Thorax 2008, 63:549-554.

9. Salhi B, Troosters T, Behaegel M, Joos G, Derom E: Effects of pulmonary rehabilitation in patients with restrictive lung diseases. Chest 2010 , 137:273-279.

10. van 't Hul A, Gosselink R, Hollander P, Postmus P, Kwakkel G: Training with inspiratory pressure support in patients with severe COPD. Eur Respir J 2006, 27:65-72.

11. Hawkins P, Johnson LC, Nikoletou D, Hamnegard CH, Sherwood R, Polkey $\mathrm{Ml}$, Moxham J: Proportional assist ventilation as an aid to exercise training in severe chronic obstructive pulmonary disease. Thorax 2002, 57:853-859.

12. Borel JC, Wuyam B, Chouri-Pontarollo N, Deschaux C, Levy P, Pepin JL: During exercise non-invasive ventilation in chronic restrictive respiratory failure. Respir Med 2008, 102:711-719.

13. Bianchi L, Foglio K, Porta R, Baiardi R, Vitacca M, Ambrosino N: Lack of additional effect of adjunct of assisted ventilation to pulmonary rehabilitation in mild COPD patients. Respir Med 2002, 96:359-367.
14. Shneerson JM, Simonds AK: Noninvasive ventilation for chest wall and neuromuscular disorders. Eur Respir J 2002, 20:480-487.

15. Gigliotti F, Spinelli A, Duranti R, Gorini M, Goti P, Scano G: Four-week negative pressure ventilation improves respiratory function in severe hypercapnic COPD patients. Chest 1994, 105:87-94.

16. van Weert E, Hoekstra-Weebers J, Otter R, Postema K, Sanderman R, van der Schans C: Cancer-related fatigue: predictors and effects of rehabilitation. Oncologist 2006, 11:184-196.

17. American Thoracic Society: Standardization of Spirometry, 1994 Update. Am J Respir Crit Care Med 1995, 152:1107-1136.

18. ATS statement: guidelines for the six-minute walk test. Am J Respir Crit Care Med 2002, 166:111-117.

19. Kendrick KR, Baxi SC, Smith RM: Usefulness of the modified 0-10 Borg scale in assessing the degree of dyspnea in patients with COPD and asthma. J Emerg Nurs 2000, 26:216-222

20. Jones PW, Quirk FH, Baveystock CM, Littlejohns P: A self-complete measure of health status for chronic airflow limitation. The St. George's Respiratory Questionnaire. Am Rev Respir Dis 1992, 145:1321-1327.

21. Redelmeier DA, Bayoumi AM, Goldstein RS, Guyatt GH: Interpreting small differences in functional status: the Six Minute Walk test in chronic lung disease patients. Am J Respir Crit Care Med 1997, 155:1278-1282.

22. du Bois RM, Weycker D, Albera C, Bradford WZ, Costabel U, Kartashov A, Lancaster L, Noble PW, Sahn SA, Szwarcberg J, et al: Six-minute-walk test in idiopathic pulmonary fibrosis: test validation and minimal clinically important difference. Am J Respir Crit Care Med 2011, 183:1231-1237.

23. Vogiatzis I: Strategies of muscle training in very severe COPD patients. Eur Respir J 2011, 38:971-975.

24. Borghi-Silva A, Oliveira CC, Carrascosa C, Maia J, Berton DC, Queiroga F Jr, Ferreira EM, Almeida DR, Nery LE, Neder JA: Respiratory muscle unloading improves leg muscle oxygenation during exercise in patients with COPD. Thorax 2008, 63:910-915.

25. du Bois RM, Weycker D, Albera C, Bradford WZ, Costabel U, Kartashov A, King TE Jr, Lancaster L, Noble PW, Sahn SA, et al: Forced vital capacity in patients with idiopathic pulmonary fibrosis: test properties and minimal clinically important difference. Am J Respir Crit Care Med 2011, 184:1382-1389.

26. Smith IE, Laroche CM, Jamieson SA, Shneerson JM: Kyphosis secondary to tuberculosis osteomyelitis as a cause of ventilatory failure. Clinical features, mechanisms, and management. Chest 1996, 110:1105-1110

27. Guzun R, Aguilaniu B, Wuyam B, Mezin P, Koechlin-Ramonatxo C, Auffray C, Saks $V$, Pison C: Effects of training at mild exercise intensities on quadriceps muscle energy metabolism in patients with chronic obstructive pulmonary disease. Acta Physiol 2012, 205:236-246.

doi:10.1186/1465-9921-14-22

Cite this article as: Ho et al.: Exercise training with negative pressure ventilation improves exercise capacity in patients with severe restrictive lung disease: a prospective controlled study. Respiratory Research 2013 14:22.

\section{Submit your next manuscript to BioMed Central and take full advantage of:}

- Convenient online submission

- Thorough peer review

- No space constraints or color figure charges

- Immediate publication on acceptance

- Inclusion in PubMed, CAS, Scopus and Google Scholar

- Research which is freely available for redistribution 